\title{
Hepatitis E virus seroprevalence in pregnant women in Pakistan: maternal and fetal outcomes
}

\author{
Najma Javed', Sultana H. Ullah' ${ }^{2}$, Nazli Hussain ${ }^{2}$, Munir A. Sheikh ${ }^{3}$, Ambreen Khan ${ }^{4}$, Farkhanda Ghafoor ${ }^{5}$, Rukhsana
} Firdous ${ }^{6}$, Waqar Uddin 7 , Arif N. Saqib ${ }^{8}$ and Ghazal Muhyudin ${ }^{9}$

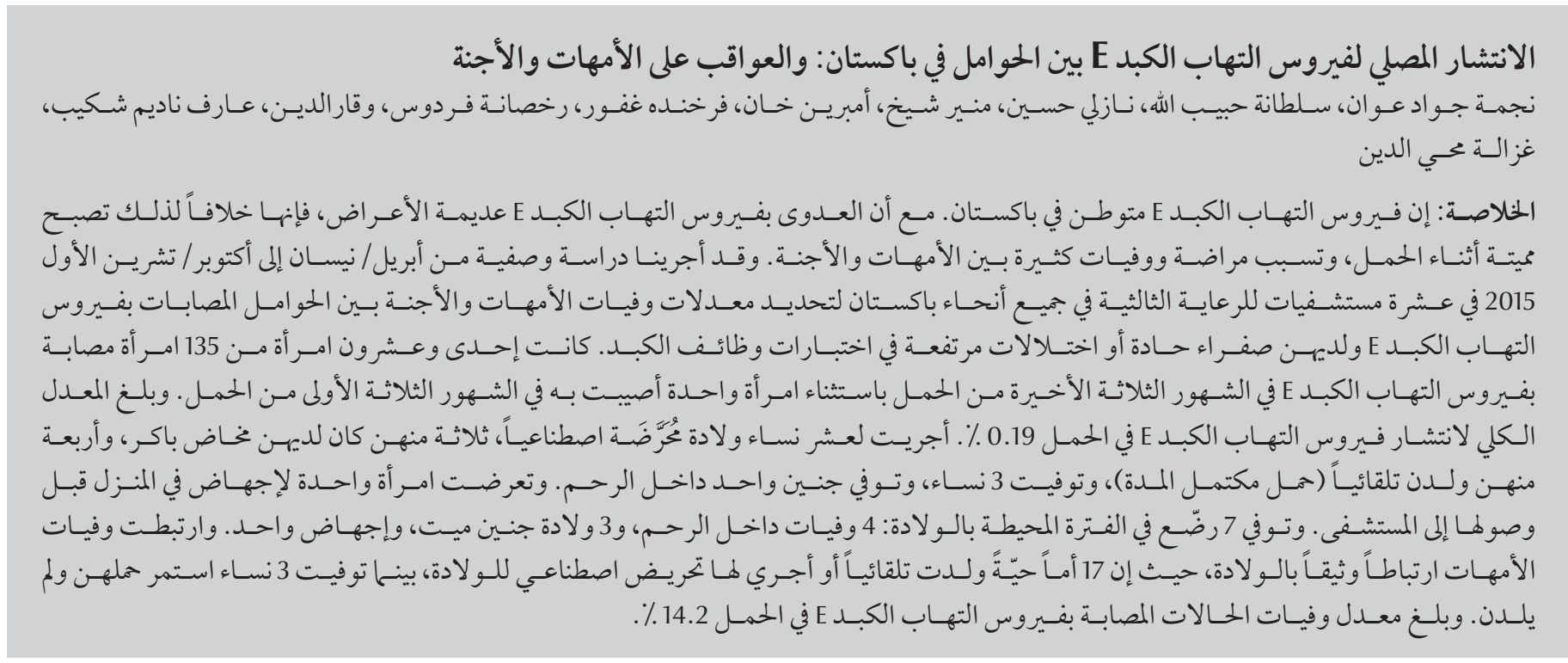

ABSTRACT Hepatitis E virus (HEV) is endemic in Pakistan. Although otherwise asymptomatic, HEV infection becomes fatal in pregnancy, with considerable maternal and fetal morbidity and mortality. We conducted a descriptive study from April to October 2015 in 10 tertiary care hospitals throughout Pakistan to determine maternal and fetal morbidity and mortality in HEV-positive pregnant women with acute jaundice or raised liver function tests. Twenty-one of 135 women were HEV positive and in 3rd trimester except for 1 in 1st trimester. Overall prevalence of HEV in pregnancy was $0.19 \%$. Ten women were artificially induced, 3 had premature labour, 4 delivered spontaneously (full term), 3 died and there was 1 intrauterine death. One woman had a home abortion before coming to hospital. There were 7 perinatal infant deaths: 4 intrauterine, 3 stillbirths and 1 abortion. Maternal mortality was significantly associated with delivery, as 17 mothers who lived went into labour spontaneously or were artificially induced, whereas 3 women who continued their pregnancy and did not deliver, died. Case fatality rate of HEV infection in pregnancy was $14.2 \%$.

\section{Séroprévalence de l'infection par le virus de l'hépatite E chez des femmes enceintes au Pakistan : conséquences sur la} santé maternelle et fotale

RÉSUMÉ Le virus de l'hépatite E (VHE) est endémique au Pakistan. Bien qu'asymptomatique dans la plupart des cas, le virus de I'hépatite E devient mortel lors d'une grossesse, contribuant de façon considérable à la morbidité et la mortalité maternelles et fœtales. Une étude descriptive à été conduite entre avril et octobre 2015 dans 10 hôpitaux de soins tertiaires dans l'ensemble du Pakistan afin de déterminer la morbidité et la mortalité chez les femmes enceintes positives au virus de l'hépatite E avec ictère aigu ou présentant une élévation des tests hépatiques. Sur 135 femmes, 21 étaient positives au virus de l'hépatite E et se trouvaient au troisième trimestre de grossesse, exception faite de l'une d'entre elles qui en était au premier trimestre. La prévalence globale du virus de l'hépatite E durant la grossesse s'élevait à 0,19\%. Dix femmes avaient subi un accouchement déclenché, trois avaient eu un travail prématuré, quatre avaient accouché naturellement (à terme), trois femmes étaient décédées et on dénombrait un décès intra-utérin. Une femme avait avorté à domicile avant de se rendre à l'hôpital. Il y a eu sept cas de décès périnatals, dont quatre cas intra-utérins, trois mortinaissances et un avortement. La mortalité maternelle était significativement associée à l'accouchement puisque les 17 mères qui ont survécu avaient accouché naturellement ou avaient subi un accouchement déclenché, tandis que trois femmes avaient poursuivi leur grossesse sans accoucher, et étaient décédées. Le taux de létalité de l'infection par le virus de l'hépatite E durant la grossesse était de 14,2\%.

${ }^{1}$ National Institute of Health, Islamabad, Pakistan (Correspondence to: Najma Awan: javed.najma@gmail.com). ${ }^{2}$ Dow Medical University, Karachi, Pakistan. ${ }^{3}$ Liaqat University of Medical and Health Sciences, Jamshoro, Pakistan. ${ }^{4}$ Khyber Medical University, Peshawar, Pakistan. ${ }^{5}$ Sheikh Zyed Medical Complex, Lahore, Pakistan. ${ }^{6}$ Bolan Medical College, Quetta, Pakistan. ${ }^{7}$ Jinnah Post Graduate Medical Center, Karachi, Pakistan. ${ }^{8}$ Pakistan Medical Research Council, Islamabad, Pakistan. ${ }^{9}$ Pakistan Medical Research Council Research Centre, Faisalabad, Pakistan.

Received: 24/06/16; accepted: 15/01/17 


\section{Introduction}

Hepatitis E virus (HEV) is a small, nonenveloped virus with a singlestranded RNA genome. The virus has four genotypes, but only one serotype. Genotypes 1 and 2 exclusively infect humans, whereas genotypes 3 and 4 also infect pigs and several other mammalian species.

Like hepatitis A virus, HEV also spreads via the faecal-oral route, and in nonpregnant women and men, the disease is usually self-limiting and has a low case fatality rate $(<0.1-4 \%)(1)$. In developing countries with poor sanitation, HEV infection is common and presents as outbreaks and as sporadic cases with acute self-limiting hepatitis.

In Pakistan, epidemics of acute viral hepatitis were first reported in the 1950s and 1960s. In 1972, an outbreak of $\sim 250$ cases was observed in an army battalion on field exercises, and all infected persons had drunk untreated river water (2). Many similar outbreaks of hepatitis $\mathrm{E}$ had been wrongly attributed to HAV. However, it subsequently became clear that all the outbreaks were caused by $\operatorname{HEV}(2,3)$. In Pakistan, HEV remains highly endemic and mainly affects the adult population (4). Several mini-epidemics have recently been reported in Pakistan and all of these appear to have been due to faecal contamination of the water supply. Although Islamabad has a supply of potable water and a good drainage system, it had a massive outbreak of acute hepatitis caused by HEV between December 1993 and March 1994 that created a lot of concern in the general population (5). The Pakistan Viral Hepatitis Surveillance System reported that during June 2010-March 2011, 712 cases of viral hepatitis were seen at 5 sentinel sites and prevalence of acute hepatitis $\mathrm{E}$ was $12.2 \%(6)$.

The prevalence of HEV is higher in pregnancy, which has mostly been reported in developing regions and countries like North Africa, India, Pakistan, Ghana and Egypt. It remains inconclusive whether the severe outcome in pregnancy in these countries reflects viral virulence, viral variants or host factors, especially malnutrition, or failure of timely and proper treatment (7). For unknown reasons, the mortality rate is higher among pregnant women, especially during the 3rd trimester (8). Fulminant hepatic failure secondary to hepatitis $\mathrm{E}$ infection is common in pregnancy and associated with a mortality rate of up to $20-25 \%$ (9). In India, Islamic Republic of Iran, Africa and the Middle East, the incidence of fulminant hepatitis was higher in pregnancy. The mortality rate in HEV-infected mothers was $100 \%$ and mother-to-child transmission of HEV was established in 50\% of cases (10).

Screening pregnant women for $\mathrm{HEV}$ is thus important for improving knowledge about the epidemiology of the virus and planning for its prevention and control. A few studies have been conducted in Pakistan to document the prevalence of HEV in pregnant women. The results of the present study will help to determine the prevalence of HEV infection in pregnant women and its outcomes at the national level. We also investigated fetal outcomes and rate of vertical transmission. Analysis of our results will help to plan future strategies to prevent the high mortality associated with this infection.

\section{Methods}

The objective of this study was to determine the maternal and fetal morbidity and mortality in pregnant women positive for HEV IgM who presented with jaundice or abnormal liver function tests, in comparison with HEVnegative cases. None of the women had jaundice of pregnancy or hepatocellular carcinoma. We conducted an observational study from 1 April to 30 October 2015 in 10 hospitals in Pakistan:
Pakistan Institute of Medical Sciences, Islamabad; Dow University of Health Sciences, Karachi; Jinnah Postgraduate Centre, Karachi, Sindh; Shaikh Zayed Hospital, Lahore; Allied Hospital, Faisalabad, Punjab; Bolan Medical College, Quetta, Balochistan; Lady Reading Hospital and Hayatabad Medical Complex, Peshawar, Khyber Pakhtoonkhwa; and Holy Family Hospital and Benazir Bhutto Hospital, Rawalpindi.

After receiving ethical clearance and consent from participating hospitals, data collectors were trained to maintain the uniformity of data coding, delivery of questions, data gathering, decoding and data entry. Data collectors were trained researchers. The questionnaire consisted of close-ended questions and information was collected under 5 headings: participating hospital, patient demography, details about hospital admission, details of laboratory findings, and outcome of pregnancy (both maternal and fetal). Any pregnant woman with acute jaundice presenting for the first time anywhere within the hospital, either in the obstetric outpatient department, labour room or emergency department, was immediately reported to the research team. After obtaining informed consent from the patients, demographic information was recorded through face-to-face interview with the patient. However, if the patient was too ill, the attending physician gave the information. Data regarding gestational age, laboratory findings [hepatitis B surface antigen, hepatitis $\mathrm{C}$ virus (HCV) antibody, liver function tests, coagulation tests (e.g., activated partial thromboplastin time)] and complications associated with pregnancy were retrieved from patients' files. All enrolled patients were followed through medical records or telephone contact after discharge for pregnancy outcomes (mother and fetus) and data were recorded.

In addition to laboratory information collected from the patients' files, pregnant women were screened for 
HEV IgM by taking 3-ml blood. Samples were transported to the designated research centre for that city where they were analysed for HEV-specific IgM antibodies using indirect antibody capture, quantitative ELISA. Sample testing used one negative and two positive controls. The ELISA kit had sensitivity and specificity of 97.9 and $100 \%$, respectively. Data on patient demography, hospital admission, laboratory findings and outcomes were analysed using Epi Info version 7.2. Descriptive analysis is presented as frequencies and percentages. A $P$ value $<0.05$ was considered statistically significant.

\section{Results}

\section{Patient characteristics}

One hundred and forty-two pregnant women were enrolled, however, $7 \mathrm{did}$ not give consent for the study and were excluded. Among the remaining 135 patients, 21 were $H E V$ positive and 114 were HEV negative.

Mean age of the HEV-positive women was 29.2 (standard deviation; $\mathrm{SD}, 7.7$ ) years and mean age of the HEV-negative women was 28.6 (4.9) years. The women were divided into 2 age groups: $20-30$ and $31-40$ years. All HEV-positive women were in the 31-40 years group, whereas $23 \mathrm{HEV}$ negative women were in the 20-30 years and 91 were in $31-40$ years group. Mean gestational age was 33.46 (4.45) weeks for HEV-positive women and 35 (2.2) weeks for HEV-negative women. Twenty-one pregnant women had acute hepatitis E. Overall prevalence of HEV among pregnant women was $0.19 \%$ (21 out of expected pregnant population of 10956$)$. One hundred and fifteen $(85 \%)$ women were multigravida and 20 (15\%) primigravida. One hundred and sixteen (86\%) women presented in the $3 \mathrm{rd}$ trimester, $17(13 \%)$ in 2 nd trimester and $2(1.4 \%)$ in 1 st trimester, and 116 presented with jaundice. All HEV-positive cases were in the 3rd trimester.

Regarding educational status, 29 were illiterate; 31 were educated to primary level, 34 to intermediate level and 23 to matric level; 11 were graduates and 7 had a masters degree.

\section{Clinical presentation}

Ten $(7.4 \%)$ of the 135 women had a history of jaundice and all those were multigravida. Jaundice was the most common symptom experienced by 116 (86\%) patients followed by nausea/ vomiting in $55(41 \%)$, pruritus in 47 (35\%) and bleeding from the gums or nose in 19 (14\%). All $21 \mathrm{HEV}$-positive pregnant women had jaundice, and jaundice to encephalopathy interval was 1-3 days. Three (14.2\%) HEVpositive patients developed encephalopathy and all died and 5 (4.4\%) of 114 HEV-negative women developed this complication and 4 died. All pregnant women with jaundice $(116,86 \%)$ were treated symptomatically

\section{Laboratory investigations}

Among the 135 patients, 7 were infected with hepatitis B virus (HBV) (3 HEV positive and $4 \mathrm{HEV}$ negative), 7 with $\mathrm{HCV}(1 \mathrm{HEV}$ positive and $6 \mathrm{HEV}$ negative) and 3 were co-infected with HBV and HCV (1 HEV positive and 2 HEV negative). LFTs, haemoglobin level, total leukocyte count, platelet count and random blood sugar were abnormal in HEV-positive and HEVnegative patients (Table 1).

\section{Maternal and fetal outcomes}

Among HEV-positive cases, 3 women died from hepatic encephalopathy and there was 1 intrauterine death (IUD) (Table 2). All babies that were born alive survived. Among HEV-negative cases, 4 women died (2 from hepatic encephalopathy and 1 each from disseminated intravascular coagulation and renal failure) as well as 6 newborns ( 3 stillbirths and 3 intrauterine deaths). Overall there were 7 perinatal infant deaths: 4 IUDs, 3 stillbirths and 1 abortion. Regarding maternal deaths, 6 died from hepatic encephalopathy and 1 from renal failure/disseminated intravascular coagulation. No significant difference was found in the laboratory findings between the fatal and surviving cases. Maternal mortality was significantly associated with delivery $(P \leq 0$ $.012)$, as 17 of 21 mothers who survived delivered naturally or were induced, while 3 who continued their pregnancy died.

\section{Discussion}

Our study showed that jaundice was more common in multigravida as compared to primigravida women. Among 20 primigravida and 115 multigravida women, 116 (86\%) presented in 3rd trimester, including all $\mathrm{HEV}$-positive cases. This means severity of HEV infection increases with repeated exposure to virus, and during pregnancy, severity increases with each trimester, becoming lethal in the last trimester. An Indian study showed that $63 \%$ of $\mathrm{HEV}$ infection was in the 3 rd trimester of pregnancy when presented with jaundice (11), and fulminant hepatic failure and death were more common in the HEV-positive group (relative risk of fulminant hepatic failure, 2.7; relative risk of death, 6.0). The current study had similar findings; out of $21 \mathrm{HEV}$-positive women, 3 developed fulminant hepatic failure and all died. However, the difference in maternal mortality between the HEV-positive and -negative groups was not significant, which may have been due to the small study group.

Abraham found that among HEVpositive pregnant women, mean gestational age was 31 weeks (12), whereas in the current study mean gestational age was 35 weeks. In another Indian study of acute liver failure (1989-1996), 49 of 83 women of childbearing age were pregnant (33 in 3rd trimester) and all except 2 had HEV infection (13). Our 


\begin{tabular}{|c|c|c|c|c|c|}
\hline \multirow{2}{*}{ Variables } & \multirow{2}{*}{ Normal values } & \multicolumn{2}{|c|}{ HEV-positive cases $(n=21)$} & \multicolumn{2}{|c|}{ HEV-negative cases $(n=114)$} \\
\hline & & Mean & SD & Mean & SD \\
\hline $\mathrm{Hb}(\mathrm{g} / \mathrm{dl})$ & $12-16$ & 9.9 & 2.069 & 9.8 & 2.0 \\
\hline $\operatorname{TLC}(/ \mu \mathrm{l})$ & $4500-11000$ & 8076 & 20501 & 7234 & 1801 \\
\hline Platelet count $(/ \mu \mathrm{l})$ & $150000-450000$ & 189860 & 168709 & 200189 & 18342 \\
\hline APTT (s) & $20-40$ & 33.4 & 9.3 & 28.5 & 7.2 \\
\hline Serum bilirubin $(\mathrm{g} / \mathrm{dl})$ & $0.2-1.0$ & 4.9 & 4.01 & 4.2 & 3.9 \\
\hline $\operatorname{ALK}(\mathrm{U} / \mathrm{I})$ & $38-126$ & 416.6 & 247.3 & 502 & 312.1 \\
\hline $\mathrm{RBS}(\mathrm{mg} / \mathrm{dl})$ & $70-115 \mathrm{mg} / \mathrm{dl}$ & 99.2 & 54.9 & 98.5 & 54.3 \\
\hline
\end{tabular}

ALK = alkaline phosphatase $; A P T T=$ activated partial thromboplastin time; HB= haemoglobin; $H E V=$ hepatitis Evirus; $R B S=$ random blood sugar; TLC = total leukocyte count.

results are consistent with these findings in that $86 \%(116 / 135)$ were in 3rd trimester at presentation and all HEV-positive patients except 1 were in 3rd trimester.

Regarding maternal mortality in HEV-positive women, Zhu et al. (14) reported high mortality (up to $30 \%$ ), mainly from fulminant hepatic failure. However, in our study, 3 of $21 \mathrm{HEV}$ positive patients died (14\%) and this may have been due to the small study population. In Ghana, HEV seropositivity in pregnancy is high at up to $29 \%$ (15), whereas our study only showed an HEV prevalence of $0.19 \%$ among pregnant women.

Regarding fetal outcomes, Khuroo and colleagues have reported that HEV infection in neonates born to HEVpositive mothers is mostly benign as neonates usually survive with no prolonged illness (16). We found a similar result and only reported 1 perinatal death from miscarriage among $21 \mathrm{HEV}$ infected mothers. A study from the United Arab Emirates showed that only a few babies of HEV-infected mothers were either preterm, had hepatitis or died within a few hours after birth (17). However, in our study there were only 2 neonatal deaths among HEV-infected mothers; 1 from IUD and another from miscarriage (10\%), which was higher than those born to uninfected mothers (5\%). In Sudan, among 39 pregnant women with HEV infection during an outbreak, there were 14 IUDs and 9 premature deliveries (18), and neonatal mortality was high compared to that in our study. A similarly high neonatal mortality has been reported in India, where $15-50 \%$ of live-born infants of HEV-infected mothers died within 1 week of birth (19). In contrast, all babies born alive from HEV-infected mothers in our study survived. Other studies have also shown that fetal morbidity in HEV-infected mothers varies from case to case and geographically, and includes miscarriage, stillbirth, preterm labour, or perinatal or neonatal death $(20,21)$.

Bhatia and colleagues have revealed that HEV-positive pregnant women had a jaundice to encephalopathy interval of 5.2 (4.4) days, serum bilirubin level of $14.4(5.8) \mathrm{mg} / \mathrm{dl}$ and serum aspartate aminotransferase/alanine aminotransferase (AST/ALT) ratio of thousands (22). However, the current study had different findings. The jaundice to encephalopathy period was 1-3 days and other laboratory values were not high.

In our study, most of the women affected were in the 31-40 years. However, an Indian study reported that most patients $(82.7 \%)$ were aged $21-30$ years (23).

A recent study from Pakistan documented that there was no history of jaundice in all 34 cases (24). Pruritus was the most common symptom experienced by $28(82 \%)$ patients, followed by jaundice in $27(79 \%)$, nausea/vomiting in 25 (74\%), encephalopathy in $18(53 \%)$ and bleeding from gums or nose in only 2 cases. Fulminant hepatic failure was diagnosed in 11 cases and all died. Similarly, in the current study only 10 patients had a history of jaundice and all $3 \mathrm{HEV}$-positive women who died eventually developed fulminant hepatic failure.

\begin{tabular}{lcccc}
\hline \multicolumn{2}{l}{ Table 2 Maternal and fetal outcomes among HEV-positive and negative pregnant women5 } & \multicolumn{2}{c}{ Fetal outcomes } \\
\hline Study population & \multicolumn{2}{c}{ Maternal outcomes } & Survival & Death \\
& Survival & Death & $19(90 \%)$ & $2^{\mathrm{a}}(10 \%)$ \\
HEV-positive, $\mathrm{n}=21$ & $18(86 \%)$ & $3(14 \%)$ & $108(95 \%)$ & $6(5 \%)$ \\
HEV-negative, $\mathrm{n}=114$ & $110(96.4)$ & $4(3.4 \%)$ & 128 & 7 \\
Total = 135 & 128 & 7 & &
\end{tabular}

a Includes 1 abortion in 1 st trimester. 
Our study had some limitations. This was a hospital-based study involving only the public sector but $70 \%$ of our population goes to the private sector, so the results cannot be generalized. In addition, discontinuation of treatment in some hospitals by patients further reduced the data.

This is believed to be the first study from Pakistan comparing clinical and laboratory profiles between $\mathrm{HEV}$-positive and -negative pregnant women with jaundice. We described maternal and fetal outcomes in pregnant women who developed hepatitis E. We showed that incidence of infection increases with duration of gestation, which suggests that pregnant women should be periodically screened for clinical features of acute hepatitis during antenatal visits and should be investigated for hepatitis $\mathrm{E}$. Pregnant women with HEV should be closely monitored for fetal and maternal well-being and signs of fetal distress, to prevent disease-associated morbidity and mortality.

Funding: We are grateful to Dr. Huma Qureshi, Executive Director, Pakistan Medical Research Council (PHRC) for her support and inputs. The study was supported by Pakistan Medical Research Council (Grant No.4-24-1/13/ $\mathrm{MCS} / \mathrm{Hep} . \mathrm{E} / \mathrm{RDC} / \mathrm{HO}$, Islamabad). Competing interests: None declared.

\section{References}

1. Hepatitis E fact sheet no. 280, revised January 2005. Geneva: World Health Organization; 2005.

2. Purcell RH, Emerson SU: Hepatitis E: an emerging awareness of an old disease. J Hepatol 2008, 48:494-503.

3. Akram M. A study of epidemic infectious hepatitis in the field. CENTO (Central Treaty Organization) Medical Conference Papers; 1975

4. Wong DC, Purcell RH, Sreenivasan MA, Prasad SR, Pavri KM. Epidemic and endemic hepatitis in India: evidence for a non-A, non-B hepatitis virus etiology. Lancet. 1980 Oct 25;2(8200):876-9. PMID:6107544

5. Malik IA, Tariq WUZ. The prevalence and pattern of viral hepatitis in Pakistan. J Coll Physicians Surg Pak. 1995;5(1):2-3.

6. Iqbal M, Ahmed A, Qamar A, Dixon K, Duncan JF, Ul Islam $\mathrm{N}$ et al. An outbreak of enterically transmitted non-A, non-B hepatitis in Pakistan. Am J Trop Med Hyg. 1989;40(4):438-43.

7. Establishment of a viral hepatitis surveillance system - Pakistan, 2009-2011. MMWR Morb Mortal Wkly Rep. 2011;Oct 14; 60(40):1385-90 (https://www.cdc.gov/mmwr/preview/ mmwrhtml/mm6040a3.htm).

8. Caro M, Kazanji M. Hepatitis E virus is highly prevalent among pregnant women in Gabon Central Africa with different patterns between rural and urban areas. Virol J. 2008;5:158 (https://virologyj.biomedcentral.com/articles/10.1186/1743422X-5-158).

9. Purcell RH, Emerson SU. Hepatitis E: an emerging awareness of an old disease. J Hepatol. 2008 Mar;48(3):494-503. PMID:18192058

10. Adjei AA, Tettey Y, Aviyase JT, Adu-Gyamfi C, Obed S, Mingle JA. Hepatitis $E$ virus infection is highly prevalent among pregnant women in Accra, Ghana. Virol J. 2009 Jul 20;6:108. PMID:19619291

11. Singh S, Mohanty A, Joshi YK, Deka D, Mohanty S, Panda SK. Mother-to-child transmission of hepatitis E virus infection. Indian J Pediatr 2003 Jan;70(1):37-9. PMID:12619951

12. Shinde NR, Patil TB, Deshpande AS, Gulhane RV, Patil MB, Bansod YV. Clinical profile, maternal and fetal outcomes of acute hepatitis E in pregnancy. Ann Med Health Sci Res. 2014 Jul;4(Suppl 2):S133-9. PMID:25184080

13. Abraham P. Viral hepatitis in India. Clin Lab Med. 2012 Jun;32:159-74. PMID:22726997
14. Khuroo MS, Kamili S. Aetiology and prognostic factors in acute liver failure in India. J Viral Hepat. 2003 May;10(3):224-31. PMID:12753342

15. Zhu FC, Zhang J, Zhang XF, Zhou C, Wang ZZ, Huang SJ, et al. Efficacy and safety of a recombinant hepatitis $\mathrm{E}$ vaccine in healthy adults: a large-scale, randomised, doubleblind placebo-controlled, phase 3 trial. Lancet. 2010 Sep 11;376(9744):895-902. PMID:20728932

16. Khuroo MS, Kamili S, Khuroo MS. Clinical course and duration of viremia in vertically transmitted hepatitis E virus (HEV) infection in babies born to HEV-infected mothers. J Viral Hepat. 2009 Jul;16(7):519-23. PMID:19228284

17. Kumar RM, Uduman S, Rana S, Kochiyil JK, Usmani A, Thomas L. Sero-prevalence and mother-to-infant transmission of hepatitis E virus among pregnant women in the United Arab Emirates. Eur J Obstet Gynecol Reprod Biol. 2001 Dec 10;100(1):9-15. PMID:11728649

18. Rayis DA, Jumaa AM, Gasim GI, Karsany MS, Adam I. An outbreak of hepatitis E and high maternal mortality at Port Sudan, Eastern Sudan. Pathog Glob Health. 2013 Mar;107(2):66-8. PMID:23683332

19. Rasheeda CA, Navaneethan U, Jayanthi V. Liver disease in pregnancy and its influence on maternal and fetal mortality: a prospective study from Chennai, Southern India. Eur J Gastroenterol Hepatol. 2008 Apr;20(4):362-4. PMID:18334884

20. Verghese VP, Robinson JL. A systematic review of hepatitis E virus infection in children. Clin Infect Dis. 2014 Sep 1;59(5):68997. PMID:24846637

21. Ahmed A, Ali IA, Ghazal H, Fazili J, Nusrat S. Mystery of hepatitis e virus: recent advances in its diagnosis and management. Int J Hepatol. 2015; 2015:872431. PMID:25692043

22. Bhatia V, Singhal A, Panda SK, Acharya SK. A 20-year singlecenter experience with acute liver failure during pregnancy: is the prognosis really worse? Hepatology. 2008 Nov;48(5):157785. PMID:18925633

23. Bhadade R. De' Souza R, More A, Harde M. Maternal outcomes in critically ill obstetrics patients: A unique challenge. Indian J Crit Care Med. 2012 Jan;16(1): 8-16. PMID:22557826

24. Javed N, Saqib MAN, Mumtaz F, Jabeen S, Rauf B, Tabassum A. Retrospective analysis of acute hepatitis $E$ infection in hospitalized pregnant cases. Pak J Med Res. 2014 OctDec;53(4):89-92. 